\title{
Distributive justice, stability, and sustainable water resources management
}

\author{
Paul Jeffrey \\ Cranfield Water Science Institute, Cranfield University. Cranfield. Beds. MK43 OAL. \\ Email:p.j.jeffrey@cranfield.ac.uk
}

\begin{abstract}
The problem of stability in distributive justice arrangements is a contemporary theme of interest to students of political and environmental theory. Progress on translating theoretical insights into practical tools has, however, been impeded by an incongruence between the subject's prescriptive and descriptive traditions. In this contribution, a literature review is used to outline the issue of stability and its characterisation as a desirable societal attribute by theorists, and to discuss the emerging complex model of distributive justice behaviour as exposed by empirical research. Incongruences between the two fields as they relate to the promotion of stability is highlighted and concepts of requisite variety are proposed as a framework within which the complex model may be exploited in order to promote stability. The ramifications of this framework for the distributive justice research agenda and appropriate resource distribution policies are explored using water resources as a focus for debate.
\end{abstract}

Keywords: Distributive justice. Stability. Requisite Variety. Water Resources 


\section{INTRODUCTION}

The roots of sustainability as a focus of concern lie in the emergence of a set of environmental challenges to our continued survival on the planet. Within the context of water policy, these challenges are exacerbated by the need to ensure reliable, safe, adequate water supplies to support the livelihoods of our communities and maintain environmental functions. In order to fairly satisfy these diverse and often complicated sets of demands on the available resource, distribution criteria are required. But on what basis should we decide on a particular set of criteria, and is there any evidence to suggest that one basis for reaching agreement on the criteria to be applied is any more robust / effective than others ? The field of research on social justice has a contribution to make to these debates, although, as we shall see, the evidence from its empirical and theoretical branches do not appear to be complimentary.

Issues of Social Justice, in terms of the concept's distributional, relational, and procedural variants, are attracting increasing comment across a variety of disciplines and applications (see Smith, 1997 for a contemporary example). However, it is symptomatic of much research in the field, that the clarity of acquired knowledge and consequently, the application of that knowledge, is restricted by a lack of crossfertilisation between the field's theoretical and empirical arms. In the particular case of research on distributional justice, these shortcomings are characterised by the distinction between prescriptive studies (with one foot firmly in the realm of philosophy), and descriptive studies (typically under the sovereignty of sociologists or psychologists). Informed comment concerning the issues upon which these two strongly related fields of knowledge have mutually beneficial contributions to make is rare and several prominent contributions to the literature have commented on the detrimental effects of this isolationism which impoverishes both traditions (e.g. Hegtvedt, 1992). Neither is such a debate exclusively pertinent to the theoretical wing of political philosophy. Late twentieth century concerns over pathways of sustainable development and the equitable management of finite natural resources would clearly benefit from practical guidance on issues of distributional justice. In the particular case of equitable water resource distribution, the conflict between a search for generally applicable criteria for resource allocation and the diversity of encountered contexts has long been highlighted as a hindrance to effective policy making (White, 1957). Informed by these criticisms, this text seeks to bridge the gap by drawing evidence from various sources to address a central theme of the normative literature and one which has broader implications, specifically for the development of sustainable resource management. The distributional justice theme is that of stability and the sustainable resource management context is water allocation.

The following text first seeks to outline the meaning and significance of stability to issues of social justice by reviewing the relevant prescriptive literature. Stable social arrangements are shown to be a central precept of desirable distributive justice configurations. Following this, the evidence from empirical studies is shown to 
present a problem for the prescriptive aspiration to stability by exposing an increasingly complex model of both distributive and procedural justice behaviour. The literature reporting various experimental approaches to exposing distributive justice sentiments suggests that individual preferences for distributive justice criteria are sensitive across a range of dimensions (context, culture, space etc.). Reconciliation between the two arms of the field, to the benefit of practical applications, is demonstrated by reference to concepts of 'requisite variety'. In particular, the development of suitable policies that take into account the complex nature of distributive justice sentiments is shown to be promoted by the adoption of requisite variety as a desirable policy attribute. Many of the concepts presented below have been covered by previous authors in various contexts. Where we seek to contribute is by providing some structure and direction to a number of disparate knowledge sets and ideas which share a common application domain. The integration of the various knowledge sets is a genuinely interdisciplinary exercise, achieving a coherent, structured, and focused analysis. Theoretical and empirical contributions from several disciplinary fields are drawn together and focused on a specific issue which is of relevance to each one. In practical terms, the work provides a possible theoretical framework for the multi-principle or complex model of distributive justice behaviour that may benefit both practitioners (politicians / policy makers) and researchers.

Although this text directly addresses the theme of just and stable water resource distribution arrangements, it is explicitly also concerned with the issue of sustainable water resource management. As noted by Haughton (1998), 'sustainability (also) requires attention to distributional equity'. Despite the (generally) undiluted focus on homo-sapiens as the central benefactors of sustainable futures, surprisingly little work has been carried out concerning the dynamics of sustainable societies themselves. In particular, there has been a bias in research into sustainability towards isolating and identifying modes of non-sustainable behaviour which in turn has focused attention (and here no criticism is intended), on the ecological and environmental aspects of sustainable development. However, the search for desirable and achievable modes of sustainable development also requires an understanding of those human centred behavioural, social, and organisational characteristics which promote sustainability. The fundamental concern here is that without some knowledge of the determinants of adaptive change at the societal level, we will be unable to design more resilient modes of development. An emphasis on safeguarding the quality and quantity of the earth's natural resources can only ever be a partial solution to the sustainability challenge. The effective and efficient exploitation of the resource base within desirable social milieux presents our societies with an equally important test. Some understanding of the dynamics of community adaptation is in many ways a pre-requisite for advancements in other areas of sustainable development (e.g. sustainable modes of production and the design of institutions that foster sustainability). There is a well established literature focused on the contribution of flexibility and co-operation as enhancers of resilience / survival. (e.g. Kempis, 1991). Similar notions of the 
'mechanics of resilience' have also been adopted in fields as diverse as Production Planning (Epstein, 1978) and Human Geography (Cosmides, 1989), providing a generic framework for identifying and analysing the processes and components of adaptive systems. Contextual relevance has been provided by other literature streams from social anthropology (both historical and contemporary) and social ecology, where the development and eventual decline of societies has been discussed in terms of their internal complexity and dynamic interaction with an external environment (Tainter, 1988; McGlade, 1995). It is this socio-political perspective which constitutes a focus for the work reported here; specifically, the issue of distributive justice and the particular case of water resource distribution.

\section{PRESCRIPTIVE EMPHASIS ON THE IMPORTANCE OF STABLE JUSTICE ARRANGEMENTS}

The stability of distributive justice arrangements is a key thematic component of the prescriptive literature on distributive justice. Stability is a significant issue for research and comment within the distributive justice field because its achievement is widely seen as a prerequisite for a viable community. For example, the work of John Rawls provides a clear example of the significance placed on stability as a desirable characteristic of distributive justice arrangements. Rawls makes stability an explicit criteria for his 'justice as fairness' framework (Rawls, 1971). The emphasis on stability emerges as a consequence of seeking conditions which promote a 'well ordered society'. A central feature of this goal is that citizens have a normally effective sense of justice which engages them to generally comply with society's basic institutions which they regard as just. The significance of the stability issue to Rawls' contribution can be gauged by the fact that a revised, and arguably more refined discussion of its attainment constitutes a major part of one of his most recent publications (Rawls, 1993). It might be noted that this revision was prompted as much by the growing body of relevant descriptive research as well as by critiques contributed by other political philosophers. In the introduction to his book 'Political Liberalism' Rawls acknowledges the central role of stability in political philosophy whilst noting that the problem of stability has played very little role in the history of moral philosophy. The importance of stability as a criteria for judging rival distributive justice arrangements is emphasised by his statement that 'If a conception (of justice) fails to be stable, it is futile to try to realise it.' The significance of stability is explicitly captured in this statement. In the absence of stability, inter-group and inter-personal frictions emerge, promoting conflict and inefficiency. Hence, (and of consequence for arguments presented below) stability is something which is to be controlled via appropriate distributive justice arrangements.

As a body of knowledge, the prescriptive literature has been keen to clarify the nature of stability and to distinguish its various applications. Some discussion of the theorists' intended interpretation of the terms 'stability' and 'instability' is thereby 
warranted. The term stability is most commonly used in the prescriptive literature as a synonym for 'lasting agreement'. Here, a concern for the stability of the contract that represents the agreement entered into by the various parties is reflected rather than the stability of the particular configuration of justice criteria that has been determined. Hence, the final distributive justice arrangement may include an agreement to allow for discrete alterations to previously fixed distribution criteria under certain circumstances. The significance of stability relates here to social arrangements (and through social arrangements to economic and political ones), and is characterised by explicit agreement concerning some form of distributive justice arrangement. It should be noted that an agreement of this type would constitute a framework of right (the realm of philosophy); effectively bounding considerations of good (the realm of politics). An appropriate example of this interpretation of stability is that one concept of justice is 'more stable than another if the sense of justice that it tends to generate is stronger and more likely to override disruptive inclinations'.(Rawls, 1971: 454) The benefits of stability are thereby in the form of reduced incidences of attempted disruption.

Within a distributional justice context, the notion of instability commonly refers to the tendency of individuals to act in ways incommensurate with an agreed set of justice principles In this tradition, movements away from stability have been characterised as being of two types; those resulting in a tendency to defect (e.g. the free-rider problem), and those resulting in a tendency to press for renegotiation of the justice contract. Within a distributive justice context therefore, instability is a reflection of the level of satisfaction felt by individuals with regard to a previously agreed set of justice principles. The ramifications of these two types of instability impact upon contrasting areas of society. Instabilities related to the free-rider problem are evident primarily in social and economic settings where individuals seek to reap the benefits of a just distribution arrangement without fulfilling their agreed duties. Contrastingly, instabilities of the second type (a tendency to press for renegotiation) constitute a prime stimulus for political activity. Indeed, changes of policy or government in democratic settings and revolutions in totalitarian settings can be viewed as the process of such renegotiation.. It is interesting to note that within the descriptive literature, these two problems are often referenced but rarely discussed, although the former does receive expansive attention from other research fields such as game theory and micro-economics (see, for example; Dawes \& Thaler, 1998; Andreoni, 1988; Kim \& Walker,1984)

Prescriptive frameworks for just water resource allocation are poorly developed outside the area of general resource distribution theories. Because water use is such a fundamental aspect of human life, and current water distribution arrangements are typically the product of historical processes based on concepts of rights and norms, there has been little motivation to intervene with new ways of organising and justifying access. Indeed, some authors have called for urgent action to fill the prescriptive void (Wouters, 1997). However, as tension and conflict over water 
distribution arrangements increases, more attention is being given to alternative distribution models. For example, the United Nations has recently, following decades of study and debate, produced a framework convention relating to the nonnavigational uses of international watercourses (United Nations, 1997). Perhaps the most significant aspect of this declaration is the endorsement of the principle of 'equitable' and 'reasonable' utilisation. Other approaches are also attracting renewed interest with recent prescriptive writings from the fields of environmental ethics (Feldman, 1995), and economics (Haddad, 1999).

\section{DESCRIPTIVE EVIDENCE FOR A COMPLEX MODEL OF ATTITUDES TO JUSTICE}

Whilst prescriptive contributions attempt to define, or at least bound, 'the kinds of social arrangements that can be defended' (Barry, 1989) the descriptive literature seeks to explain how individuals select between different justice criteria. Early theories concerning distributive justice behaviour fell into two distinct theoretical frameworks. On the one hand, equity theories proposed that a distribution occurring within a relationship will be equitable and just when the relations between the inputs brought into the relationship and the outcomes strived for in the relationship are perceived as being equal for all participants. Alternatively, multi-principle theories proposed the existence of several different justice principles which govern human actions and judgements. Here, a number of rules and principles are used to determine distributions that are deemed just according to social consensus under certain circumstances. Empirical studies have supported this second framework and the multi-principle or complex model is now dominant (Miller, 1991).

Support for a complex model of distributive justice behaviour has come from both the theoretical and empirical traditions. Theorists have long hinted at the existence of a multiple parameter model. For example, Hume wrote that justice is only necessary where there is both limited benevolence and scarcity of goods (Hume, 1962). More recently, Sandel remarked that given a high level of benevolence, people will not insist on their just share, concluding that justice appears as a remedial virtue, whose moral advantage consists in the repair it works on fallen conditions (Sandel, 1982). Both these examples indicate that the writers of prescriptive treatises are broadly aware of (if not necessarily sensitive to) the complex nature of individual justice sentiments. Empirical support for a complex model of distributive justice behaviour is widespread. The complexity observed in these studies relates to variations to selected distribution criteria across respondent, resource type, and context. Broadly stated, individuals modify their opinion of what is a just distribution criterion as the details of the situation evolve. For example, with regard to variances in resource availability, Hegtvedt found a positive correlation between reward scarcity and the type of justice criteria selected (Hegtvedt, 1987). Under conditions of resource scarcity, equality was the preferred criteria, whereas under conditions of resource abundance, equity was the 
preferred principle. It has also been found that that views on entitlement are related to both gender and occupational type (Moore, 1991). Further evidence suggests that different spheres of human action are associated with variances in the preferred principles of justice (Hochschild, 1981). Other empirical research has exposed evidence that chosen criteria for resource distribution are influenced by changes in resource type (Foa \& Stein, 1980), the personal relationships between the donor and recipient (Peterson, 1975; Austin, 1980), group dynamics (Brewer \& Kramer, 1986), social goals (Deutsch, 1975), and internalised normative values Rasinski, 1987).

Bringing the theoretical and empirical traditions together, Soltan, comments on a number of previous studies and suggests that individual beliefs concerning justice issues are ambiguous and confused (Soltan, 1987). However, others have interpreted this and related findings as suggesting that individuals carry several competing views of justice which are applied in different contexts (Miller, 1991). A sense of justice is thereby not a simple 'one rule for all cases' phenomena, but rather a complex, contextually sensitive set of considerations A similar conclusion has been reached by other investigators and is perhaps most succinctly stated thus: 'Inconsistency is not automatically evidence of hypocrisy. People simply have a hard time reconciling their conflicting concerns in a changing world. Justice is not a stable, well defined ideal end state toward which people purposefully move; rather it is a dynamic, ever shifting equilibrium between the excesses of too little regulation on the one hand and too much on the other.' (Mitchell et al, 1993)

The emerging complex model of distributive justice behaviour discussed above, describes a contextually sensitive criteria set that is focused on those variables that can be identified as influencing distributive justice judgements. In summary, the literature suggests that variances in distributive justice judgements can be influenced by considerations regarding the resource itself (the object), by considerations regarding the recipient of the resource (the subject), or by variances which describe the individual or group of individuals determining the distribution (the allocator[s]). Empirical research is thereby some way towards developing a descriptive model of distributive justice sentiments that takes account of both differences in resource, subject and arbitrator characteristics and the complexity of the interactions amongst them. A complete model will take account of those structural and dynamic components that reflect the nature, interaction and influence of past experiences and their rationalisation into considered opinion. (By structure here is meant the nature of those factors that contribute towards considerations of justice related issues and the format of relationships between them. By dynamics is meant the relative magnitude and direction of influences that occur between the relevant factors). Furthermore, it is perhaps more appropriate to talk of a configuration of criteria rather than a single criterion. Distributive justice behaviour will then be described by a context sensitive set of criteria, the emphasis of which is driven by the details of what is being distributed, to whom, and by whom. Such an arrangement may be unstable as a rule set but that does not prevent it from promoting stability of the kind discussed earlier. 
Hence, there are two possible descriptions of stability. Firstly it could be defined as that configuration of justice criteria that exhibits the least contextual fluctuation. However, the achievement of stability in these terms may or may not promote the stability of the arrangement itself or influence the propensity of individuals to press for its modification. As a footnote it should be pointed out that although experimentation has revealed the complexity of distributive justice behaviour, there has been little advance in providing a comparable theory or model against which further empirical work can be tested. Therefore, the construction of a theoretical ideal that can be proffered as a working model of distributive justice behaviour constitutes a research agenda for many currently active in the field.

It is only comparatively recently that detailed studies have been carried out to describe individual and group perceptions of equitable water distribution issues. Pierce (1979) attempted, with limited success, to relate personal value systems to preferences for water allocation priorities. A study by Syme \& Fenton (1993) found some evidence to support Rasinski's two factor (equality and proportionality) model of equity (Rasinski, 1987) but concluded that these were insufficient to describe the range of philosophical attitudes underpinning allocation preferences. Latterly, Syme and Nancarrow (1996 and 1997) have enriched the debate by showing that whilst individuals are able to identify and articulate a wide range of environmental justice philosophies, judgement of fairness in a particular case is influenced by multiple considerations, several of which have a spatial aspect. In their concluding statements they remark that the evaluation of a fairness heuristic may vary over time and according to political and social circumstances. Additional evidence for spatial variance in attitudes to the fairness of water allocation decisions has come from studies of water transfers. For example, Keenan et al (1999) recently concluded that people's perspectives on water transfers are strongly influenced by local economic conditions and social characteristics. These studies demonstrate that individuals and communities exhibit wide variations in both the bases upon which they make judgements about just allocations of water resources and the nature of the resultant justice criteria.

\section{BRIDGING THE GAP}

Having reviewed the prescriptive and descriptive literature strands (which respectively relate to the significance of stability and evidence for a complex model of distributive justice behaviour), we would now clarify the focal issue of this contribution. The previous two sections showed firstly that stability is a central concern of political philosophers in that it is a desirable characteristic of the social arrangements which they seek to describe. Secondly, empirical research demonstrates the complexity of distributive justice behaviour, suggesting that consensus and agreement (the very pillars of stability) are elusive phenomena. In broader terms, prescriptive (philosophic) contributions imply a search for a universally agreeable 
framework that will guide the selection of criteria for utility / resource distribution. However, empirical research indicates that such a framework is a distant and possibly complex objective.

The ramifications of this discontinuity between the two fields of study can be readily witnessed in domestic political terms. Parties who's policy approach to resource distribution issues is driven by broad ideological principles continually struggle to come to terms with the complex sentiments of their constituents. The resulting instability, as described by Rawls and others, is a continuous proclivity on the part of those who feel the present contract to be unjust, to press for its amendment; through lobbying, through the ballot box, or via other, less peaceful means. A particularly significant example of where the instability of a distributive justice arrangements causes frictions and inefficiencies is in the area of public resource provision. Here, the complexity of distributive justice sentiments are reflected by a single (in the case of a totalitarian regime) or at most half a dozen (in the case of democracies) simplified justice criteria that vie for popular support. The distributive justice configurations that are proffered by political parties are themselves commonly derived from narrow ideological premises that take little account of the contextual or temporal dynamics of reality. The challenge here is to promote greater stability by exposing a framework within which the incongruence highlighted above can be reconciled.

We would propose that a useful approach for achieving such a reconciliation can be found in the analogies from evolutionary theory which formed the basis of work carried out by W. Ross Ashby and his colleagues on Cybernetics (Ashby, 1952 \& 1956). In particular, Ashby's theory of 'requisite variety' (later expounded and applied in management thinking by Stafford Beer) can be seen as both explaining how instabilities of the types discussed above occur, and offering a framework for developing more stable configurations. In simple terms, Ashby's theory of requisite variety states that only variety can manage variety. That is, if disturbance or instabilities are to be managed then the number of discrete states available to a control system must match the states available to that which is being controlled. The analogy which drives Ashby's proposition is that of the activities of a brain. In biological terms, the variety of the control system (the brain) enables adaptation and thereby the stability of the organism. Similarly, in ecology, diversity at the level of individual behaviour or physiology can be viewed as the source of adaptivity for the species or community. Both 'adaptivity' and 'stability' are terms used explicitly (and with some precision) by Ashby to refer to the maintenance of the system within specified performance limits. The process is thereby dynamic and the system may exhibit a variety of behaviours or states within the acceptable limits.

The relevance of these propositions to distributive justice issues may not be immediately clear. However, we would reiterate the central objective of this contribution which is to suggest a more definite framework for thinking about the complex, multi-principle model of distributive justice behaviour which emerges from 
the descriptive sources. Our purpose is not so much to reconcile the prescriptive and descriptive literatures as to describe a way forward for both; a task which requires some synthesis of theory. Within this context, requisite variety may firstly explain why instabilities occur. Taking the distributive justice arrangement to be a form of stability control, we may postulate that such arrangements which do not reflect the diversity of sentiments exhibited by the society's members effectively fail the requisite variety test. In practical terms, this failing can be seen as the lack of variety encapsulated in resource distribution policies as adopted by broad political groupings. Instabilities (particularly in the form of demands for renegotiation) arise partly because political ideologies fail to encompass a significantly complex model of distributive justice sentiments. Democratic forms of government clearly do present members of a society with a choice of ideologies at regular intervals, and the adaptive potential embodied by such changes may indeed be a contributing factor to the longevity of these particular types of regime. Despite this natural advantage of pluralist systems over single party ones, there are two characteristics of modern democracies which serve to constrain the benefits of diversity. Firstly, most parties which compete for influence in modern democracies are committed to maintaining the dominance of a very narrow band of justice sentiments. Debates about the distribution of resources are founded on a collective acceptance of a particular just arrangement, variety being expressed only through different preferences for wealth redistribution. Reference to the criteria for resource distribution is made only as a response to crises or by what are seen as extremist groupings which operate at the edge of the political spectrum. Secondly, the frequency with which the opportunity to effect substantive changes in policy occurs is dictated by a purely arbitrary timescale. The global drivers which influence resource distribution dynamics (climate, technology, conflict, scarcity, etc.) are unlikely to be operating at the same tempo as the four or five year cycle of elections which typify most democracies.

Following on from an appreciation of the cause of instability, it is possible to discuss ways of promoting it. Using the concept of requisite variety as a template for thinking about the problem, we may propose that stability could be enhanced by either a reduction in the variety of distributive justice opinions to more closely match available policy instruments, or, conversely, by an increase in the variety represented in policy instruments to match that exhibited by society's distributive justice opinions. The former of these two options, whilst being a perfectly valid process for achieving requisite variety, poses its own set of instability questions. Achieving a reduction in the variety of distributive justice sentiments implies restrictions on freedom of opinion / speech and a (forceful ?) rejection of the plurality which characterises our modern societies. This alternative should therefore be rejected on the grounds that the process of its attainment would promote the very instabilities which we are hoping to avoid. The second option (that of increasing the variety represented in policy instruments to match that exhibited by society's distributive justice opinions) suffers from no such deficiencies and thereby represents an achievable path to desirable change. 
Considering our chosen context for a moment, it might be useful to elaborate on the notion of requisite variety as it might pertain to resource distribution issues. Resource distribution problems are typically resolved through the often strained alliance between a society's political and economic systems. The former dictates a criteria on which resource distribution claims are to be reconciled whilst the latter (in its widest sense) constitutes the device through which distribution is effected. Distributive justice arrangements based on concepts of requisite variety would promote stability through adaptive potential. The rules for distributing resources would be context dependent and reconfigure to more closely match complex, temporally variable social sensitivities regarding need, equality, and equity. The environment in this context can be thought of as the availability and quality of resources available for distribution. The implication here is that there is no particular moral or procedural reason why resources should be distributed according to the same criteria under all conditions. Instability is characteristic of arrangements which are inflexible and unresponsive to changing circumstances and in this sense, democracy and the free market are as potentially inflexible as dictatorship and central planning. Agreement on how, and under what circumstances, resource distribution arrangements should adapt, will, at the very least, create a framework for debate about change which anticipates the sources of potential conflict. For example, under conditions of impending scarcity of a primary resource (water, food, etc.), such debates may consider modifications to resource distribution principles which move away from a system based on merit with minimum guarantees through social security provision, to one based on need.

It would be negligent to proceed any further with the central arguments of this text without referring to several authors who have alluded to the problem of requisite variety as it relates to the issue of distributive justice. Although these writers often use a vocabulary strikingly different to the one adopted above, their frame of reference and focus of concern strongly reflects the subject matter of this article. Two prominent contributions of this type are evident.

Perhaps the clearest attempts to address the issue of multi-principle conceptions of justice is to be found in the works of Michael Walzer and John Rawls (although the two theorists are commenting on subtly different aspects of the issue). Walzer points out that historically, a wide variety of arrangements and ideologies are displayed, arguing that 'to search for unity is to misunderstand the subject matter of distributive justice.' (Walzer, 1983) He thereby explicitly recognises the problems which the empirical literature poses for a single prescriptive distributive justice formula. Walzer is directly addressing the plurality of principles of justice here, indicating that the search for a single system or ranking of distributive justice principles is misplaced. Although Walzer's own hypothesis of 'complex equality' has not been beyond critical comment ( In particular, we would guide the reader in the direction of the critiques presented in Cohen [1993] and in Gill [1987]), his formulation of the problem remains a forceful and succinct statement of the need for a multi-principle approach. 
On the other hand, John Rawls's sensitivity to the complexity issue is concerned with the pluarilty of comprehensive moral doctrines that could lead (in Rawls' opinion) to an agreed set of distributive justice principles. Whilst the text of 'A Theory of Justice' does not indicate a specific concern for the issue (although reference is made to Ashby's work on equilibrium \& stability), the writings contained in 'Political Liberalism' (which was fashioned in direct response to the various critiques of his previous work), does contain reference to the problem. For example, Rawls asks the question:' How is it possible that deeply opposed though reasonably comprehensive doctrines may live together and all affirm the political conception of a constitutional regime.'. This query sets an agenda that would serve moral and political theorists as a focal research question. It also raises the possibility that societies may be forced to accommodate multiple, reasonably comprehensive, distributive justice arrangements. Rawls is clearly concerned with the problem of how a diversity of conceptions concerning how a just arrangement can be achieved can lead to an arrangement that is just for all. Contrastingly, Walzer sees nothing wrong with a multiplicity of views on the principles of distributive justice. The two contributions are sensitive in different ways to the complexity of the human condition, and both affirm that it is the variety inherent in our opinions that constitutes a central problem for reaching a workable system of distributive justice arrangements.

We now turn to an interpretation of the requisite variety model in practical terms using resource distribution policy as a focus. Firstly, we suggest some examples of how the details of resource distribution policies can reflect the need for requisite variety. Although it is true that a suite of resource distribution policies could not be all things to all people at all times (the distribution criteria upon which they are based being mutually exclusive or incompatible in many instances), the emerging complex model of distributive justice behaviour provides an opportunity to develop policies with greater levels of variety (in the Ashby sense) that will, in turn, promote greater stability. It may initially appear that the introduction of a complex model would create additional problems as decision makers would be faced with a multi-dimensional criteria set. However, it would be a mistake to assume that a complex model is necessarily complicated. A more accurate description would point out that it is not dominated by a single, orthodox justice sentiment. Also, by offering a greater level of flexibility, the complex model of distributional justice behaviour promotes policy instruments that are more responsive to the contextual and temporal dynamics that characterise long term distributive justice problems. Secondly, we discuss how the details of a multi-principle theory might be exposed empirically. Although progress towards a complex model of distributive justice behaviour has been driven largely by the empirical literature, there remains opportunities for exploring specific types of variety which would be of interest to policy makers 


\section{CAPTURING VARIETY IN POLICY INSTRUMENTS}

It is not the purpose or intention of this contribution to suggest specific policy options for resource distribution problems. The discussion presented in this section is therefore quite correctly of an abstract nature, dealing in the conceptual rather than the functional / operational aspects of the subject-matter. It should be born in mind that both this and the previous section constitute an interpreted extrapolation of the foregoing discussions and as such are intended as propositional rather than prescriptive.

Before we suggest some concrete illustrations of the application of the concept of requisite variety within the context of distributional justice, it is important to reject one possible interpretation of the approach. Our intention is not to minimise the variety of justice principles so that resultant policies are merely representations of the lowest common denominator. Reference to the seminal works on Cybernetics suggests that diversity can only be controlled by diversity (Beer, 1972). The objective is therefore to capture the diversity of distributive justice principles in more sensitive policy frameworks. Interpersonal agreement on the practical application of distributive justice principles is more likely if the principles themselves are contextually sensitive in the same way that individual opinions are. In political terms, the nature of resultant policy frameworks will reflect a diversity of distinct criteria (rankings, rules etc.) for resource distribution rather than comprehensive doctrines (ideologies, ethical systems etc.) via which to arrive at such criteria. This implicit criticism of current political systems views contemporary social institutions as tools for controlling rather than managing the complexity of values, opinions and convictions which enrich our societies. As recently reviewed by Rhee (1998), similar explanations of the relationship between complex societies and the institutions which serve them have been posited by writers in other fields. In particular, the contribution of Luhmann (1984) regarding the 'adequate complexity' achieved by legal systems is of relevance as it builds on a normative description of the problem.

Policy frameworks which reflect the need for requisite variety will quite possibly be more complex than those in evidence at present but not inevitably more complicated. The types of complexity which might be reflected would relate to a number of dimensions of the resource distribution problem; resource type, resource availability, quantity of resource available, quality of resource available, relationship of distributor to recipient of resource, perceived value or utility of resource etc.. Suitable policies may reflect public sensitivities to these issues by allowing for changes in the criteria applied dependent upon the particular context. For example, the criteria for distributing water resources for drinking may differ from those for distributing water resources for irrigation. Similarly, some distinction may be drawn between the criteria for distributing water resources on the basis of quality and quantity. Access to better quality water would be judged on different grounds from access to more water. 
Likewise, distribution criteria may undergo modification dependent upon the amount of resource available with a distinction being made between conditions of surplus, sufficiency and scarcity. This is perhaps the most obvious area where greater diversity could be built into water resource distribution policies. Some empirical findings have already been generated, opening the way for policy scientists and politicians to embody the issue in their approaches to resource distribution problems (e.g. Foa \& Stein, 1980). A suitable policy in this respect may match distribution criteria with resource availability through any one of a range of mechanisms. We might conjecture on this point and suggest a graded progression of distribution criteria to correspond with differing levels of water availability. Hence, periods of plenty may attract a distribution criterion based on equity, periods of sufficient supply might be reflected by a criterion based on equality and a period of water scarcity could be matched with a criterion based on need.

As noted above, distinguishing between different resource types also provides opportunities for developing classifications of resources, enabling different frameworks of control to be derived for each. There is little rational reason why the same distribution criteria that are applied to clean drinking water should be applied to the distribution of sub-potable water for irrigation. Allowing a single ideological framework to drive an assessment of just distribution for both, clearly ignores the lessons of the requisite variety model because there is evidence that individuals have different attitudes to each resource. Approaches to water distribution policy making which capture the variety of justice sentiments may also develop mechanisms for locating water of differing qualities within an assemblage of resources, the order of which reflects community preferences. One potential outcome of this way of thinking about resource distribution is that politicians may be faced with a classification of resources ranked in order of their significance to different parts of the community. Some trans-national bodies already exhibit this approach to resource distribution, often based on theories of rights rather than of justice. Perhaps the most obvious example is the UN declaration of human rights which details a listing of resources (abstract as well as physical) which people are entitled to as a basic human right. Unlike associations of communities with mutual interests (such as the UN), domestic political groupings are typically founded on broad ideological principles from which they derive suitable distributive justice criteria.. However, the specifics of context force an interpretation of ideological doctrines, which often leads to varying interpretations and exposes undesirable consequences. In terms of Rawls' query concerning the reconciliation of a plurality of comprehensive doctrines, an administrative system that is unencumbered by ideology is clearly more able to formulate and manage policy frameworks that are capable of representing the complexity of individual sentiments. For example, given a situation where individual justice sentiments are variable over both space and time, and where the competing claims of different communities on the same water source are granted equal standing in terms of the rationality of the demands, accommodation can be achieved through exploiting the complexity of justice sentiments. Actual distribution arrangements will 
be necessarily flexible and context dependent, and will seek to promote the long term health of the water source itself as an objective of common interest. Collective identity between communities can emerge through an understanding of the common as well as the relative significance of the resource.

It should be noted that an emphasis on contextually sensitive solutions reflects comments recently made by Aaron Wolf when reporting his significant work on distribution agreements for international water-sheds. Wolf speaks of 'a middle ground between the absolute uniqueness of each basin (which implies the futility of searching for common principles) and the feasibility of delineating clear and guiding principles for allocations which would work like an algorithm for all the international waters of the world ' (Wolf, 1999) The application of ideas of requisite variety suggest that not only should inter-basin needs and settings influence distribution criteria, but that spatial and temporal variations in water availability, water quality, level of need etc. within the basin itself should also be allowed to influence allocations. This is an implicit recognition of the coevolutionary aspects of effective water management as it accepts that water has a fundamental role to play in supporting agriculture, leisure activities, freshwater habitats, local and regional economies, regional development and public health (an agenda reflected in the recent UN convention [United Nations, 1997]). Such a reactive (adaptive?) strategy would both ensure that sustainable water resource arrangements were negotiated rather than imposed, accommodate the need for geographical equity as recently highlighted by Haughton (1998), and provide some resilience in the face of global threats such as population growth and climate change (as noted in Miller et. al., 1997). It also has two significant corollaries; it would require the implementation of monitoring schemes to provide information on the current and anticipated status of waters and dependent systems, and it would clearly involve a more intense and participatory form of water-shed governance.

Finally, we would make some comment on the nature of policy implementation processes. Generating requisite variety in policy options is a largely futile exercise unless the variety can be made use of. This is essentially a distinction between flexibility (the generation of options for change) and adaptability (the capacity to move to new configurations). If the requisite variety model means designing policies which exploit more than one distribution criteria according to resource level, then the ability to design and manage the changeover from Criteria ' $A$ ' to Criteria ' $B$ ' is an important one. There are clearly ramifications here for both the formulation of legislation and the administration of government. If legislation is considered the most effective way of formalising distributive justice arrangements (and there is no assumption here that it is), then the mechanisms for exploiting variety need to be written into law. Alternatively, if a more self-regulating (government intervention rather than control) approach to resource distribution issues is adopted, adaptation will be largely influenced by broader social and market mechanisms. 


\section{MODIFICATIONS TO THE RESEARCH AGENDA}

As reviewed above, several dimensions to the complex model are well understood and receive ongoing attention from researchers. The aim of this section is therefore to suggest an expanded (as opposed to a new) agenda for the research field by drawing on the model of requisite variety to guide further empirical studies. In general terms, if requisite variety is to be built into policy mechanisms then the type of knowledge required will have as much to do with the dynamics of individual perceptions of distributive justice as it has to do with the mechanics of selected distribution criteria. To elaborate on this point, the variety of distributive justice sentiments is primarily a function of individual sensitivities to changes in the context of the resource distribution problem. The attitude of a single individual towards issues of distributive justice therefore changes over time as part of a dynamic interaction. An appropriate research agenda should therefore be concerned with identifying and characterising the nature of this dynamic. Research questions need to query the process of formulating just resource distributions and not just the nature of the final selection.

In general terms individual sensitivities to changes in resource type offer an as yet poorly explored area. The vast majority of studies carried out with the aim of examining individual or group resource distribution behaviour have utilised money as the unit of resource. Results from these surveys have arguably been the dominant source of information during the early development of the complex model. However, the use of monetary values as the focus of distributive justice decisions may provide an abstracted indication of distributive justice sentiments by leaving open the issue of what recipients are to do with the obtained resource. Relative levels of monetary reward can only be used as a very broad indicator of desired resource distribution. A monetary value of itself has relevance only in a cultural and economic context. As a resource, money is neutral and the sentiments that influence individual behaviour in relation to it are thereby determined by the respondent's attitude towards its role and use. Hence, monetary values are an abstracted indicator of general well-being and as such can only provide an incomplete picture of the complexities of distributive justice sentiments. (e.g. precluding any distinction between resource quantity and resource quality or between varying levels of resource availability). Therefore, a move away from the use of monetary values as a measure of utility constitutes a further enrichment of the complex model. By using distinct resource types, a richer picture of individual sentiments concerning just allocations of key societal resources can be developed. Such an approach will allow subjects to both indicate the relative significance of resource types, and distinguish between resource quality and quantity. It should be noted however that the use of discrete resource types is not expected to expose high levels of agreement concerning selected distribution regimes. There is no evidence from the distributive justice literature to suggest that individuals agree to any greater extent on the appropriate distribution of say health care, than they do on the distribution of monetary rewards. Despite this, if one looks a little further afield, the work of Maslow on hierarchies of need, provides an indication of what might be 
expected from subjects when they are asked to rank resources in order of significance (Maslow, 1970).

Moving on to consider the omnipresent and increasingly important issue of water resource distribution as a focus for discussion, another area where the variety of individual justice sentiments could be better exposed by empirical study concerns the effect of levels of resource availability on respondents' choice of distribution criteria. As noted above, we may expect to observe some variety in selected distribution criteria as the level of water availability moves from plenty, through sufficiency to scarcity. At what point do certain individuals change their preferred criterion ? Do these changes occur at different points for different qualities of water or for different uses of water? The use to which water is put and the circumstances of the user can be anticipated to be significant modifiers of justice sentiments. The value of an identical volume and quality of water is variable across individuals within the same community. How is the equity of this phenomenon perceived by members of the community or by a neighbouring community with a different water use profile ? Is the criterion selected by an individual under conditions of plenty an indicator of either the propensity to change criterion under conditions of scarcity or the nature of the altered criterion ? Empirical research could contribute to providing responses to these queries by exploring behaviour at the boundaries between different resource availability levels.

The influence of cultural environment on selected distribution criteria represents a specific and important dimension to the distributive justice research agenda. Ever greater levels of global economic and political integration, and increasing pressure on both natural and other types of economic resources have created a problem for policy makers as they seek a framework within which cross-culturally just resource distributions can be derived. Both socio-anthropological and sociological approaches are required to expose the nuances of culture and history which make water distribution an issue of such emotive force. Specific research agendas might address the question of how cultural norms influence justice sentiments concerning water distribution, and whether or not there are commonalities of perception or attitude between cultures which can form a basis for the development of collective distribution criteria ? It is no longer sufficient to merely expose differences in cross-cultural attitudes to just resource distributions. Policy makers will require information concerning the sources or determinants of these differences. Clearly, achieving requisite variety of distributive justice arrangements will be more problematic on a global scale than on a regional or national one. However, realising cross-cultural distributive justice arrangements constitutes the most important challenge for the multi-principle model. 


\section{CONCLUSION}

The broad objective of this contribution has been to develop a synthesis of the prescriptive and descriptive research strands to the benefit of both the academic and practitioner communities The requisite variety analogy has been found to be of intuitive use in many fields of study and practice outside of its original home in Cybernetics. As individuals and societies we are always keen to learn of new methods which promise greater control over ourselves and others. As noted above, Ashby's writings on cybernetics took their inspiration from the behaviour of biological systems, in particular the function of monitoring and control systems such as the brain. This biological analogy is also applicable in a wider context with regard to the stability of the distributive justice arrangement. In systemic terms, survival is ensured through adaptive change which in turn is promoted by the generation of diversity or variety in sub-systems. For example, the survival of communities of organisms is promoted by diversity of individuals' physical or behavioural characteristics. If we view the issue of stability as relating to 'the contract that represents the agreement entered into by the various parties rather than the particular configuration of justice criteria that has been determined', then the relevant level at which diversity is required is that of the criteria. In other terms, the resilience of the agreement will be promoted by the diversity of criteria represented in it.

As a footnote, it is relevant to draw attention to a potential source of difficulty that arises when the requisite variety model is transferred from the field of Cybernetics to that of distributional justice. The traditional aim of political philosophy has been to derive modes of social arrangement that promote general well-being; a goal that has encouraged a focus on the attainment of harmony and agreement as opposed to discord and dispute. As noted above, the requisite variety model was adapted by Ashby and others from processes which they observed in biological systems; processes which often result in great suffering and distress for those organisms caught up in the evolutionary imperative. This peculiarity of human focused systems (the desire or need to promote a 'good' outcome), and its contrast with other biological systems has been identified and discussed elsewhere (Merrell,1966; Jeffrey, 1996). The pertinence of the distinction for this text is that it encourages a cautious approach to analogy transfer and prompts us to pay greater attention to the mechanisms and processes of the requisite variety model across different applications.

Finally, we would emphasise that the incongruence between the descriptive and prescriptive arms of the distributive justice literature is not of immediate consequence in terms of knowledge generation. Neither is it a significant worry with regard to seeking or promoting understanding of the ways in which issues of justice are or should be addressed. The motivation for pursuing the 'theoretical accommodation' outlined above has been a concern for the practical application of the contributions made by both arms of the field. Identifying just and feasible resource distribution policies (guided by economic or social imperatives) is a challenge faced daily by 
public bodies. The potential for academic input to resolving these problems has been stifled by a lack of synthesis between the theoretical and experimental traditions, leading to a continuing reliance upon narrow ideological dogmas which both fail to reflect the breadth of individual sensitivities and preclude contextual modification. What we hope to have provided here is a broadening of the framework for discussing the use of 'compound criteria'. Both the descriptive and prescriptive traditions have indicated their awareness of this approach in different terms. However, the increasing relevance of the subject matter's policy implications suggest that closer co-operation is required so as to design resource distribution arrangements which are sensitive across several dimensions of the resource - donor - receiver envelope. The requisite variety model provides a useful focus for such co-operation.

\section{Acknowledgements}

I am grateful for financial support received from the European Commission under the EPPM (Contract \# EV5V-0486) and Aquadapt (Contract \# EVK1-CT-2001-00104) projects. The final version of the manuscript also benefited from conversations with several colleagues, prominent amongst whom were Nick Winder, Sander van der Leeuw, Roger Seaton, and Francois Giraud.. 


\section{References}

Andreoni, J. (1988). Why Free Ride ? Strategies and learning in public goods experiments. Journal of Public Economics 37, 291-304

Ashby W. R. (1952). Design for a Brain. London: Chapman \& Hall

Ashby, W. R. (1956). An Introduction to Cybernetics. London: Chapman \& Hall

Austin, W. G. (1980). Friendship and Fairness: Effects of Type of Relationship and Task Performance on Choice of Distribution Rule. Personality and Social Psychology Bulletin. 6, 402-407.

Barry, B. (1989). Theories of Justice. Berkeley, CA: University of California Press

Beer, S. (1972). Brain of the Firm. London: Penguin Books

Brewer, M. B. and Kramer, R. (1986) Choice Behaviour in Social Dilemmas: Effects of Social Identity, Group Size and Decision Framing. Journal of Personality and Social Psychology 50, 543-49

Cohen, J. (1993). Symposium on Michael Walzer - Spheres of Justice - A Plea for Plurality and Equality. Deutsche Zeitschrift Fur Philosophie. 41, 1009-19

Dawes, R. M. and Thaler, R. H. (1988) Anomalies - Cooperation. Journal of Economic Perspectives. 2, 187-98

Deutsch, M. (1975). Equity Equality and Need: What determines which value will be used as the basis of distributive justice. Journal of Social Issues. 3, 137-49

Feldman, D. L. (1995). Water Resources Management: In Search of an Environmental Ethic. Baltimore: John Hopkins University Press

Foa, U., and Stein, G. (1980) Rules of Distributive Justice: Institutional and Resource Influences. Academic Psychology Bulletin. 2, 89-94.

Gill, E. R. (1987). Walzer on Complex Equality - Constraints and the Right to be wrong. Polity. 20, 32-56.

Haddad, B. M (1999). Rivers of Gold : Designing Markets to Allocate Water in California. Washington: Island Press 
Haughton, G. (1998) Geographical equity and regional resource management: Water management in Southern California. Environment \& Planning B: Planning and Design. 25, 279-298

Hegtvedt, K. (1992). When is a distribution rule just. Rationality and Society. 4, 30831

Hegtvedt, K. (1987). When rewards are scarce: Equal or Equitable distributions ? Social Forces. 66, 183-208

Hochschild, J. L. (1981) Whats fair ? American beliefs about distributive justice. Cambridge, MA: Harvard University Press

Hume, D. (1962). A treatise on human nature. Glasgow: Fontana / Collins

Jeffrey, P. (1996). Evolutionary Analogies and Sustainability: Putting a Human Face on Survival. Futures. 28, 173-87.

Keenan, S. P., Krannich, R. S., and Walker, M. S. (1999). Public perceptions of water transfers and markets: Describing differences in water use communities. Society and Natural Resources.. 12, 279-292.

Kim, O., and Walker, M. (1984). The Free Rider Problem: Experimental evidence. Public Choice. 43, 3-24

Luhmann, N. (1981). Ausdifferenzierung des Rechts (The Differentiation of Law), Frankfurt:.Suhrkamp

Maslow, A. H. (1970). Motivation and Personality. London: Harper \& Row

Merrell, D. J. (1966). Evolution and Genetics New York: Holt, Reinhart and Winston

Miller, D. (1991). Recent Theories of Social Justice. British Journal of Political Science. 21, 371-91.

Miller, K. A., Rhodes, S. L., and Macdonnell, L. J. (1997) Water allocation in a changing climate: Institutions and adaptation. Climatic Change.. 35 (2), 157-177

Mitchell, G., Tetlock, P. E., Mellers, B. A., and Ordonez, L. (1993). Judgements of Social Justice: Compromises between equality and efficiency. Journal of Personality and Social Psychology. 65, 629-39.

Moore, D. (1991) Entitlement and justice evaluations: Who should get more and why. Social Psychology Quarterly. 54, 208-23. 
Peterson, C. (1975) Distributive Justice Within and Outside the Family. Journal of Psychology. 90, 123-27.

Rasinski, K. (1987). Whats Fair is Fair - Or is it ? Value Differences Underlying Public Views About Social Justice. Journal of Personality and Social Psychology. 53, 201-11

Rawls, J. (1993) Political Liberalism. New York: Columbia University Press

Rawls, J. (1971) A Theory of Justice. Oxford: Oxford University Press

Rhee, Y. P. (1998) Normative systems theory for sustaining democracy. World Futures. 52, 75-94

Sandel, M. (1982) Liberalism and the limits of Justice. Cambridge: Cambridge University Press

Smith, D. (1997). Back to the Good Life: Towards an Enlarged Conception of Social Justice. Environment \& Planning D. 15, 19-35.

Soltan, K. E. (1987). The Causal Theory of Justice. Berkeley, CA: University of California Press

Syme, G. J., and Fenton, M. D. (1993) Perceptions of equity and procedural preferences for water allocation decisions. Society and Natural Resources. . 6, $347-$ 360.

Syme, G. J., and Nancarrow, B. E. (1996). Planning attitudes, lay philosophies and water allocation: A preliminary analysis and research agenda. Water Resources Research. 32(6), 4003-4010

Syme, G. J., and Nancarrow, B. E. (1997). The determinants of perceptions of fairness in the allocation of water to multiple uses. Water Resources Research. 33(9), 2153-2163.

Tainter, J. A. (1988). The Collapse of Complex Societies. Cambridge: Cambridge University Press

United Nations, (1997). Convention on the law of non-navigational uses of international watercourses. Adopted by the UN General Assembly and Opened to Signature, May 21, 1997. 
Walzer, M. (1983). Spheres of Justice: A Defence of Pluralism and Equality. Oxford: Blackwell

White, G. (1957). A perspective of river basin development. Journal of Law and Contemporary Problems. 22, 186.

Wolf, A. T. (1999). Criteria for equitable allocations: the heart of international water conflict. Natural Resources Forum. 23, 3-30.

Wouters, P. (1997). Present Status of International Water Law. in Wouters, P. (Ed) International Water Law. Selected Writings of Professor Charles B. Bourne. London: Kluwer Law International 